\title{
Opposition to Oncomouse
}

SIR - Your reporting on the European opposition to patents for the Harvard Oncomouse (Nature 361, 103 \& 574; 1993) concentrates on the opposition generated because the mouse is "designed for suffering". That may indeed be a concern, but there are other more important issues involved in the matter of "patents on life". At least some of the opposition is motivated by matters separate from animal rights.

The opposition to the oncomouse patent is part of a pattern of opposition to the patenting of any form of genetically altered organism. Organisms that have been 'designed for suffering' have been with us for some time. They have been developed by ordinary methods of selection. Sometimes the purposes for which they were bred have been rational, for example athymic nude mice. Sometimes they have been irrational, for example the incredibly unhealthy purebred dogs that practising veterinarians such as myself have to deal with.

What is different about the newer form of genetically engineered organisms is that their developers are now demanding the protection of governments for their economic interests. This attempt to use the state to enforce a monopoly means that genetic engineering is now a matter of public interest rather than a private economic or research concern.

Large vested interests are too often assured of the protection of government for the promotion of their own interests. The public surely has a right to question how its tax dollars are spent. The institutions that develop genetically engineered organisms are usually the recipients of large sums of public largesse whether directly or indirectly. If the public's money is being spent, the public has a right to intervene in how it is being spent. This is part of a larger struggle for democracy and participation that is one of the characteristic trends of our time. It should also be noted that allowing an individual or institution to gather further economic benefits from the use of public money seems to violate elementary standards of fairness.

There is also the matter of how the granting of patents on life is situated in our economic system. Practising veterinarians are more than aware of how some aspects of agriculture have become monopolized by larger corporations given the advantages that government already provides to such institutions. Patents on genetically engineered organisms will only encourage this trend to monopoly agriculture. Is this a desirable outcome? Does it not conflict with the desire for more democracy and more individual and local control? Is it right to allow corporations to use the powers of government further to disempower individuals in our society?

\section{Pat Murtagh}

Mobile Veterinary Services,

700 Henderson Hwy,

Winnipeg, Manitoba R2K 2J8,

Canada

\section{Wrath averted}

SIR - In your Commentary "Forty years of molecular information" (Nature 362, $783-784 ; 1993$ ) you state that I recalled the biochemistry department from Oxford travelling together to Cambridge to look at the DNA structure. This is incorrect. The group that travelled consisted of Sydney Brenner, Jack Dunitz and myself (none of us from the department of biochemistry). Please correct this to prevent historical inaccuracy, as well as to protect me from the wrath of my colleagues.

\section{Leslle E. Orgel}

Salk Institute,

Chemical Evolution Laboratory,

PO Box 85800 ,

San Diego,

California 92186-5800, USA

\section{Opportunitistic infection}

SIR - You rightly call for "a better understanding of the way in which the existence of a substantial pool of people with serious immune suppression may contribute to the emergence of virulent forms of other infections, tuberculosis for example"1. In fact, although the contribution to the development of more virulent forms is not yet clear, there are already a number of well-argued cases of AIDS sufferers incubating opportunistic pathogens and then acting as reservoirs and passing these secondary diseases on to others.

Chave $e t a l .{ }^{2}$ have reported five cases of Pneumocystis carinii pneumonia (PCP) in renal transplant patients who shared the waiting room and some of the treatment rooms of a Swiss clinic with AIDS patients, as well as an increase of PCP in cancer patients coincidental with increased registration of AIDS cases. Bodsworth, Cooper and Donovan ${ }^{3}$ have studied the passing of hepatitis-B (HBV) from AIDS patients to others.

There is at least one documented example of transmission of multidrug-resistant tuberculosis from an HIV-positive patient ${ }^{4}$. And Fitzgerald, Grzybowski and Allen have traced the coincident rises of HIV and tuberculosis in an extensively documented study ${ }^{5}$.

Because the secondary infections which AIDS sufferers incubate are most dangerous to those with weak immune defences ${ }^{6}$, the dangers are greatest in the hospital environment. AIDS sufferers must obviously be isolated from other patients with weak immune defences. The idea of an AIDS ward also becomes questionable because AIDS sufferers are probably most dangerous to other AIDS sufferers.

The dangers to the general healthy community also ought not to be underestimated. For tuberculosis endangers everyone and not just the immunosuppressed.

\section{Frank J. Leavitt}

The Lord Immanuel Jakobovits

Center for Jewish Medical Ethics,

Faculty of Health Sciences,

Ben Gurion University of the Negev,

Beer Sheva,

Israel

1. Nature 362, 13(1993).

2. Chave, J.P. et al. AlDS 8, 927-932 (1991).

3. Bodsworth, N. J., Cooper, D. A. \& Donovan, B. J. Infectious Diseases 163, 1138-1140(1990).

4. MMWR 40, 129-131 (1991).

5. Fitzgerald, J., Grzybowski, S. \&Allen, E. Chest 100 191-200 (1991).

6 Bronnimann, D. A. et al. Ann. int. Med. 106, 372-379 (1987).

\section{One too many}

SIR - Daedalus is a strange and mysterious creature, who may well carry 24 pairs of chromosomes ${ }^{1}$. Personally I am satisfied with only 23 pairs, a number I share with almost all other humans ${ }^{2}$.

Bengt 0. Bengtsson

Department of Genetics,

Sölvegatan 29,

S-22362 Lund,

Sweden

1. Jones, D. Nature 362, 594 (1993).

2. Tjio, J. H. \& Levan, A. Hereditas 42, 1 (1956).

\section{Un morceau}

SIR - The British Library has purchased the William Petty papers from Lord Shelburne for $£ 1$ million. .

A million pounds was paid, Iread ${ }^{\prime}$, To satisfy Lord Shelburne's need. (It would be libellous, I fear,

If "greed" for "need" were written here! Sir William's papers, maps and things,

For decades hidden in the wings,

At last will publicly be seen.

The British Library, I ween,

Will soon expose, for our delight,

These works, so long obscured from sight.

It took more cash than I have got

Topurchase such a Petty lot.

\section{Andrew Dale}

Department of Mathematical Statistics,

University of Natal,

Durban, 4001.

South Africa

1. Nature 361, 4 (1993) 